\title{
Inhibition of Neointimal Hyperplasia Development by MCI-186 is Correlated With Downregulation of Nuclear Factork B Pathway
}

\author{
Geethalakshmi Radhakrishnan, BDS; Ryoko Suzuki, PhD; Hironori Maeda, MD; \\ Morio Yamamoto, MD; Nobuyuki Hirose, MD; Rajesh Katare Gopalrao, MD*; \\ Gang-Hang Lee, $\mathrm{PhD}^{* *}$; Yoshihiro Hayashi, $\mathrm{PhD}^{* *}$; \\ Parijatha Rao, $\mathrm{PhD}$; Shiro Sasaguri, MD
}

\begin{abstract}
Background Atherosclerosis is a progressing inflammatory response mediated by various signaling molecules among which nuclear factork B (NFK B) is thought to have a pivotal role. This study demonstrated the efficacy of antioxidant MCI-186 in preventing the progression of atherosclerosis by inhibiting signaling molecules such as NFK B.

Methods and Results Balloon injury of intima was performed in the right common carotid artery of Japanese male white rabbits, which were then fed a $1 \%$ high cholesterol diet for 4 weeks, after assigning them to either the control $(\mathrm{n}=7)$ or MCI-186 $\left(0.5 \mathrm{mg} \cdot \mathrm{kg}^{-1} \cdot \mathrm{day}^{-1}, \mathrm{n}=7\right)$ group. Histological analysis revealed a reduction in neointimal thickness and lipid deposition in the subendothelial area of the MCI-186 group. Immunohistochemical analysis revealed attenuation of E-selectin expression, macrophage migration and proliferation of smooth muscle cells in the MCI-186 treated group. In in vitro studies, rabbit aorta smooth muscle cells were incubated with rIL$\mathbb{B}$ in either the presence or absence of MCI-186. MCI-186 significantly inhibited rIL-1ß-induced proliferation of smooth muscle cells from rabbit aorta, as well as the activation of NFK B. Moreover, western blot analysis showed the inhibitory action of MCI-186 on the nuclear translocation of NFK B in human umbilical vein endothelial cells under rIL-1B stimulation.
\end{abstract}

Conclusions MCI-186 could provide a novel therapeutic strategy for atherosclerosis by inhibiting the NFK B pathway. (Circ J 2008; 72: 800-806)

Key Words: Antioxidants; Atherosclerosis; Free radicals

$A$ herosclerosis is a progressing inflammatory process that leads to the activation of endothelial cells (ECs), monocytes and smooth muscle cells (SMC)!-4 The initial step, resulting in inflammatory response, is the sensitization of ECs by the oxidative modification of low-density lipoprotein, followed by the production of chemokines, pro-inflammatory cytokines and the expression of adhesion molecules, which is concomitant with the migration of monocytes into subendothelial spaces ${ }^{3-5}$ These monocytes differentiate into macrophages that then accumulate by scavenging lipids and, eventually, the lipid-laden macrophages have to undergo cell turnover through apoptosis.,7 Furthermore, the migration and proliferation of SMC proceeds to neointimal hyperplasia and fibrous plaque formation? In addition, it has been reported that oxidative stress accelerates the progression of atherosclerosis? Free radicals, including reactive oxygen species (ROS) and reactive nitrogen species, are produced by the activation of nicotinamide adenine dinucleotide phosphate oxidase, the expression of iNOS and the secondary influence of IL- $\mathbb{B}$ and TNFa in

(Received June 17, 2007; revised manuscript received November 28, 2007; accepted December 11, 2007)

Departments of Surgery II, *Physiology and **Pathology, Faculty of Medicine, Kochi University, Nankoku, Japan

Mailing address: Shiro Sasaguri, MD, Department of Surgery II, Faculty of Medicine, Kochi University, Kohasu, Oko, Nankoku 783-8505,

Japan. E-mail: sasaguri@med.kochi-u.ac.jp

All rights are reserved to the Japanese Circulation Society. For per-

missions, please e-mail: cj@j-circ.or.jp
ECs, SMC and macrophages mediating various signaling pathways $!^{10}$

Nuclear factork B (NFk B) is a redox-sensitive transcription factor involved in the inflammatory response to oxidative stress by regulating inflammatory genes and apoptosis 11 The rel/NFK B family comprises 5 subunits; that is, relA (p65), rel B, c-rel, p50 and p52, which form either homo or hetero dimers and are characterized by the presence of a common N-terminal 'rel homology' domain. Especially, p65 has a high transcription potential to induce target genes and, moreover, p65/p50 is abundantly present in cytoplasm. In non-stimulated cells, NFK B exists as an inactive form along with an inhibitor ofk B (K B) in cytoplasm. Under inflammatory and oxidative stimulus, $\mathrm{k} B \mathrm{Ba}$, which is a wellelucidated molecule of the $\mathrm{k} \mathrm{B}$ family, undergoes phosphorylation by $\mathrm{K}$ B kinase and ubiquitinylates, thus leaving the p65/p50 form of NFK B in an activated state that then translocates into the nucleus and expresses various genes! ${ }^{2}$ The activation of NFK B progresses as a downstream in the signaling pathway involved in atherosclerosis, including modified lipoproteins, production of cytokines, adhesion molecules such as E-selectin, and SMC proliferation! ${ }^{13}$ Therefore, NFK B is universally accepted as an important target for the inhibition of atherosclerosis associated with oxidative stress ${ }^{14,15}$

MCI-186 (3-methyl-1-phenyl-2-pyrazolin-5-one; Radicut ${ }^{\circledR}$, edaravone), a potent free-radical scavenger, is currently being used in the management of acute ischemic stroke and also exhibits protective effects on myocardial infarction! 16,17 
Previous studies have demonstrated the effect of MCI-186 in attenuating ROS-induced endothelial damage, protecting against ischemia reperfusion injury and inhibiting tumor cell growth ${ }^{18,19}$ Recently, MCI-186 has been reported to possess anti-atherosclerotic effects; however, the mechanism is still not known? ${ }^{20}$ In the present study, using a rabbit balloon injury model, we examined the hypothesis that MCI-186 attenuates the progression of atherosclerosis and the mechanism of anti-atherosclerostic effect could be explained by inhibiting the signaling pathways, such as NFK B.

\section{Methods}

\section{Rabbit Balloon Injury Model}

Male Japanese white rabbits weighing 3-3.2 kg (Japan SLC, Inc, Shizuoka, Japan) were used. All animal experimental protocols were followed in accordance with the Guide for the Care and Use of Laboratory Animals published by the US National Institutes of Health (NIH Publication No. 85-23, revised 1996) and the guidelines of our university. Anesthesia was achieved by the rabbits inhaling $1.39 \%$ isofluorane with ketamine hydrochloride $(20 \mathrm{mg} / \mathrm{kg})$, and pentobarbital sodium $(50 \mathrm{mg} / \mathrm{kg})$ as the pre-anesthetic medication. Balloon injury was performed in the right common carotid artery (RCCA) using a 3-Fr Fogarty catheter (Edwards Lifesciences, Irvine, CA, USA) and inflating the balloon 3 times at $3 \mathrm{~atm}^{21}$ Animals were divided into 2 groups: control group (without treatment, $\mathrm{n}=7$ ) and MCI-186 group $\left(0.5 \mathrm{mg} \cdot \mathrm{kg}^{-1} \cdot \mathrm{day}^{-1} \mathrm{iv}\right.$, for 4 weeks, $\mathrm{n}=7$; Mitsubishi Pharma Corporation, Tokyo, Japan) and then fed a $1 \%$ high cholesterol diet (Oriental Yeast Co, Chiba, Japan) for 4 weeks. Animals were then killed, and their RCCA were harvested and fixed with either $10 \%$ formaldehyde or embedded in OCT compound (Tissue-Tek, Sakura Finetechnical, Tokyo, Japan) for histopathological analysis.

\section{Histochemical and Immunohistochemical Analysis}

Paraffin sections $(4 \mu \mathrm{m})$ were stained with hematoxylin and eosin to analyze the area of neointima and media, and cryostat-frozen sections $(6 \mu \mathrm{m})$ were processed with Oil Red O stain to quantify lipid deposition. The sections were subjected to citrate buffer $(0.01 \mathrm{~mol} / \mathrm{L}$ sodium citrate and $0.01 \mathrm{~mol} / \mathrm{L}$ citric acid) 3 times for $5 \mathrm{~min}$ in a microwave oven to detect for SMC-specific a-actin (a-SMA), proliferating cell nuclear antigen (PCNA), E-selectin and p65 NFK B. To stain macrophages, the sections were pre-treated with $0.1 \%$ pronase-E (Dako Cytomation, Glostrup, Denmark) at $37^{\circ} \mathrm{C}$ for $10 \mathrm{~min}$. The endogenous peroxidase was inhibited by immersing the sections in methanol containing $0.3 \% \mathrm{H}_{2} \mathrm{O}_{2}$ for $10 \mathrm{~min}$, and incubated with the following diluted primary antibodies: anti-macrophage Ab (RAM11, 1:50; Dako Cytomation), a-SMA Ab (1A4, 1:50; Dako Cytomation), anti-PCNA Ab (PC10, 1:10; Dako Cytomation), monoclonal FITC-conjugated anti-human E-selectin $\mathrm{Ab}$ (CD62E, 1:50; Invitrogen, Carlsbad, CA, USA) and p65 NFk B Ab (1:50; Santa Cruz Biotechnology, Inc, Santa Cruz, CA, USA), at $4^{\circ} \mathrm{C}$ overnight. The sections were processed at room temperature for $1 \mathrm{~h}$ with biotin-labeled secondary $\mathrm{F}(\mathrm{ab}) 2$ Ab (1:200; Dako Cytomation) to detect macrophage, $a-S M A$ and PCNA, followed by incubation with avidin-biotinylated peroxidase complex (Vectastain ABCAP kit; Vector Laboratories, Inc, Burlingame, CA, USA) for $1 \mathrm{~h}$. The sections were reacted with DAB solution (Sigma-Aldrich Co, St Louis, MO, USA). Fluorescein goat anti-rabbit IgG $(\mathrm{H}+\mathrm{L})$ (1:200; Molecular Probes, Tokyo,
Japan) was used to detect E-selectin and p65 NFK B.

\section{Double Immunoflourescence Staining}

To view the co-expression of E-selectin and CD-31 in RCCA sections, double immunofluorescence staining was performed. Tissue sections were incubated with CD-31 antibody, followed by incubation with FITC-conjugated antibody (Dako Cytomation). The sections were subsequently stained with anti E-selectin, and visualized using Texas Red-conjugated antibody (Invitrogen Co) counterstained with DAPI (Vector Laboratories). Images were recorded with an Axiphoto microscope (Carl Zeiss, Oberkochen, Germany), using a Keyence VB-7010 camera equipped with VH analyzer VH-H1 A5 (Keyence, Osaka, Japan).

\section{SMC Isolation and Culture}

SMCs from rabbit aorta (RASMC) were obtained using the explant technique ${ }^{22,23}$ The RASMC were seeded at $2 \times$ $10^{4}$ cells/well in 24-well culture plates and incubated overnight with DMEM and 10\% FBS. Cells were treated with varying doses of MCI-186 (ie, 0.6 or $6 \mu \mathrm{mol} / \mathrm{L}$ ) with or without IL-1 $(30 \mathrm{ng} / \mathrm{ml})$ for $60 \mathrm{~h}$. The number of cells was counted and the average was calculated from the results of 3 independent experiments.

\section{Immunocytochemistry}

Immunocytochemistry was performed to identify the nuclear translocation of NFK B. The RASMC were seeded at $0.5 \times 10^{4}$ cells/well in 8 -well Lab-Tek chamber slides (Nalge Nunc Int) and incubated overnight. The RASMC were pre-incubated with or without $6 \mu \mathrm{mol} / \mathrm{L}$ MCI- 186 for $30 \mathrm{~min}$, followed by stimulation with IL- $13(30 \mathrm{ng} / \mathrm{ml})$ for $1 \mathrm{~h}$. Cells were fixed with $10 \%$ paraformaldehyde buffer for 10 min and incubated overnight with p65 NFK B Ab (1:50) at $4^{\circ} \mathrm{C}$, and then further incubated with fluorescein goat anti-rabbit $\operatorname{IgG}(\mathrm{H}+\mathrm{L})$ secondary antibody $(1: 200)$ for $10 \mathrm{~min}$ at room temperature.

\section{Superoxide Measurement in Arteries}

The oxidative fluorescent dye dihydroethidium (DHE) was used to evaluate the in situ production of superoxide from $30 \mu \mathrm{m}$ frozen tissue sections, as described elswhere ${ }^{24}$ Cytosolic DHE exhibits blue fluorescence, but once it is oxidized by superoxide to ethidium bromide, it intercalates within the cell's DNA, staining its nucleus a fluorescent red (excitation at $488 \mathrm{~nm}$, emission $610 \mathrm{~nm}$ ). Serial sections $(30 \mu \mathrm{m})$ were equilibrated under identical conditions for $30 \mathrm{~min}$ at $37^{\circ} \mathrm{C}$ in Krebs-HEPES buffer. Fresh buffer containing DHE $(2 \mu \mathrm{mol} / \mathrm{L})$ was applied topically onto each tissue section, coverslipped and incubated for $30 \mathrm{~min}$ in a light-protected, humidified chamber at $37^{\circ} \mathrm{C}$, and then viewed by fluorescent confocal microscopy (Bio-Rad MRC-1024), using the same imaging settings in each case.

\section{Western Blot Analysis}

Western blot was used to analyze the activation of ASK-1 and NFK B. Human umbilical vein ECs (HUVEC) were cultured in $35-\mathrm{cm}^{2}$ flasks and maintained in EC medium (EBM2; Cambrex Bio Science Walkersville, Inc, Walkersville, MD, USA) supplemented with 5\% FBS, hydrocortisone $0.2 \mathrm{ml}$, hFGF $\beta 2 \mathrm{ml}$, VEGF $0.5 \mathrm{ml}, \mathrm{R}^{3} \mathrm{IGF}-10.5 \mathrm{ml}$, ascorbic acid $0.5 \mathrm{ml}$, hEGF $0.5 \mathrm{ml}$ and GA- $10000.5 \mathrm{ml}$. The HUVEC $\left(3 \times 10^{6}\right)$ were transferred into $35-\mathrm{cm}^{2}$ dishes and incubated overnight at $37^{\circ} \mathrm{C}$ with $5 \% \mathrm{CO}_{2}$. To demonstrate the effect of MCI-186 on the NFK B pathway, the HUVEC 
A

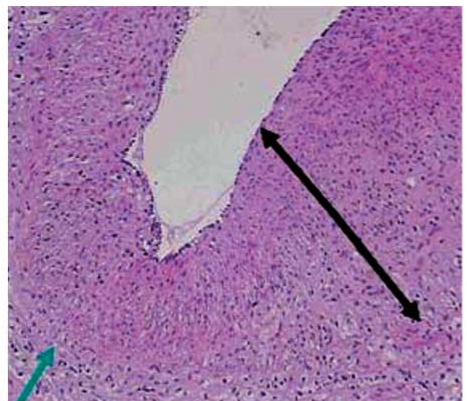

C

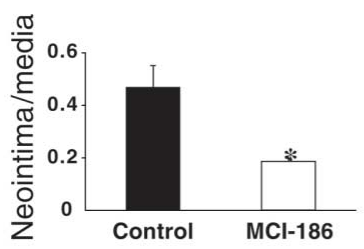

E

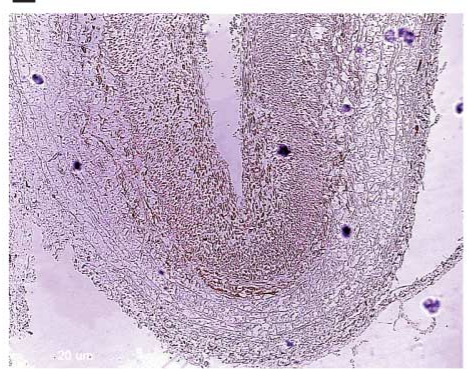

B

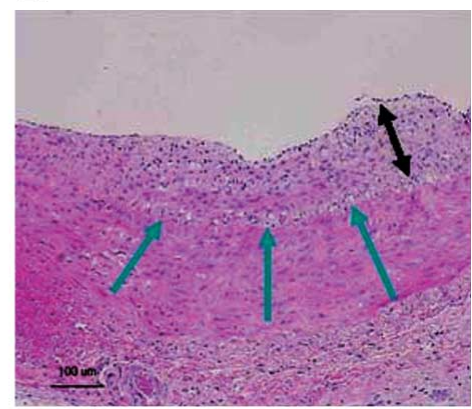

D

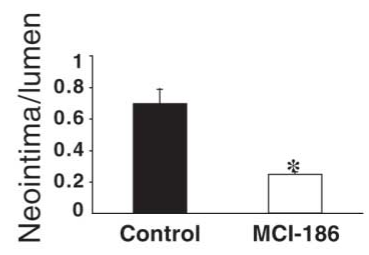

$\mathbf{F}$

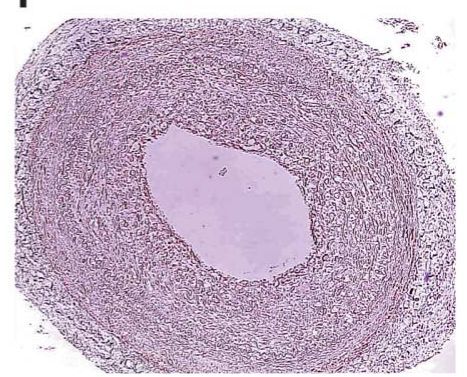

Fig 1. MCI-186 inhibited neointimal thickness in rabbit right common carotid artery (RCCA). The black arrows span the neointimal thickness and the blue arrows point to the media. (A) Increased neointimal thickness in the control group, and (B) neointimal thickness is reduced with MCI-186. Graphs show the ratio of (C) neointimal thickness/medial thickness and (D) neointimal thickness/entire vascular. In the group treated with MCI-186, neointimal thickness was inhibited ( $\mathrm{p}<0.05$ vs control group). Staining by smooth muscle cell-specifica-actin of the RCCA section from the $(\mathrm{E})$ control group and $(\mathrm{F})$ group treated with MCI-186.

\section{A Negative control}

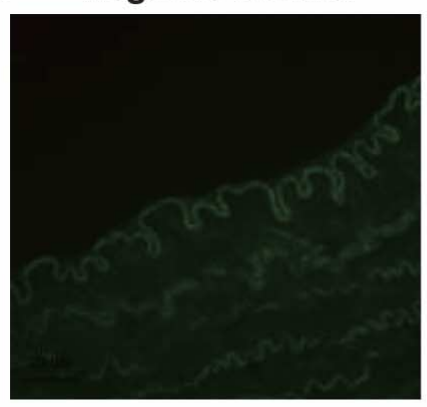

Control Gp
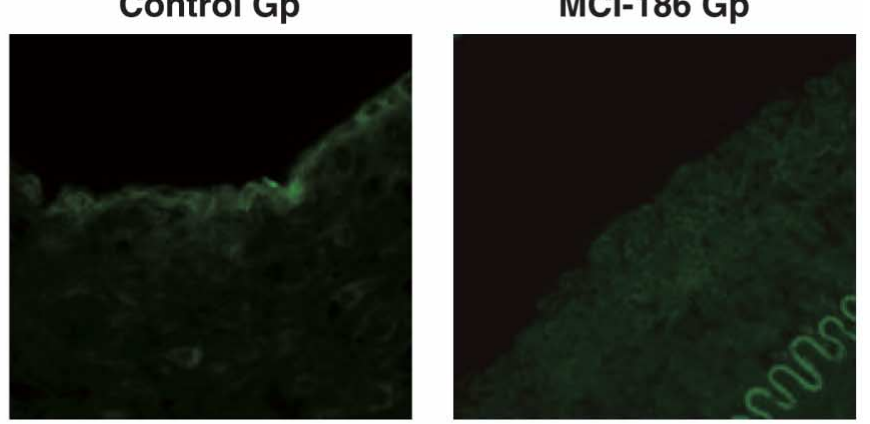

\section{B Control Gp}

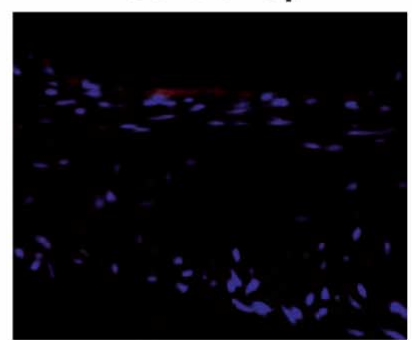

MCl-186 Gp

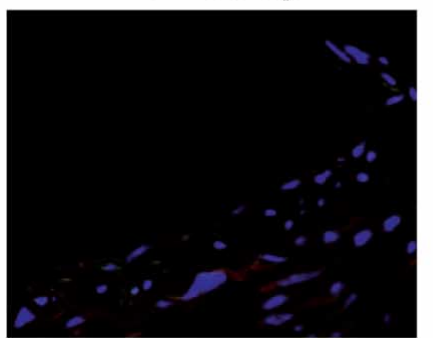

Fig 2. Inhibition of E-selectin expression by MCI-186. MCI-186 inhibited E-selectin expression on endothelial cells (ECs). (A) Immunofluorescent staining of rabbit right common carotid artery (RCCA) with anti E-selectin antibody. MCI-186 inhibited E-selectin expression on balloon-injured arteries. (B) Double immunofluorescence staining was used to localize the co-expression of E-selectin and CD31. RCCA sections from the control group revealed overexpression of E-selectin on ECs, whereas expression of E-selectin was not observed in the group treated with MCI-186. Red fluorescence corresponds to E-selectin expression. 
A

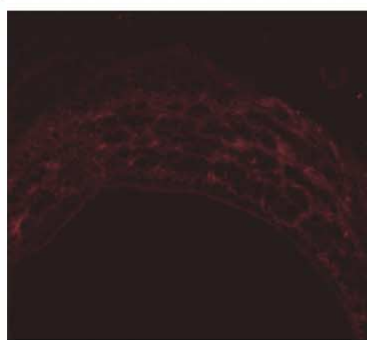

B

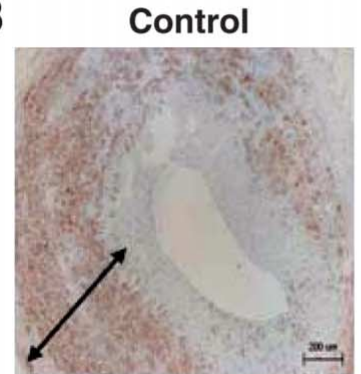

C
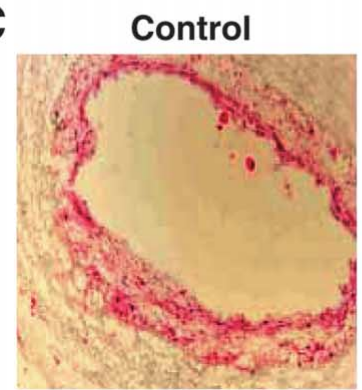

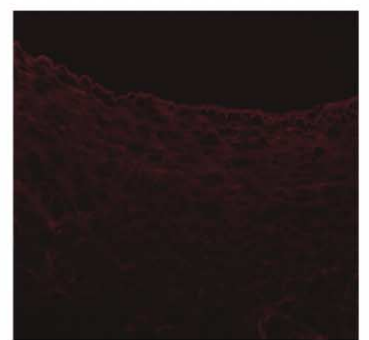

MCl-186

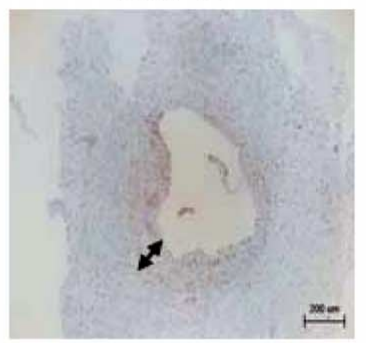

MCl-186

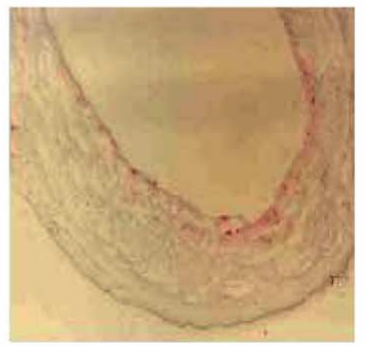

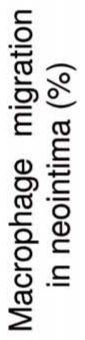
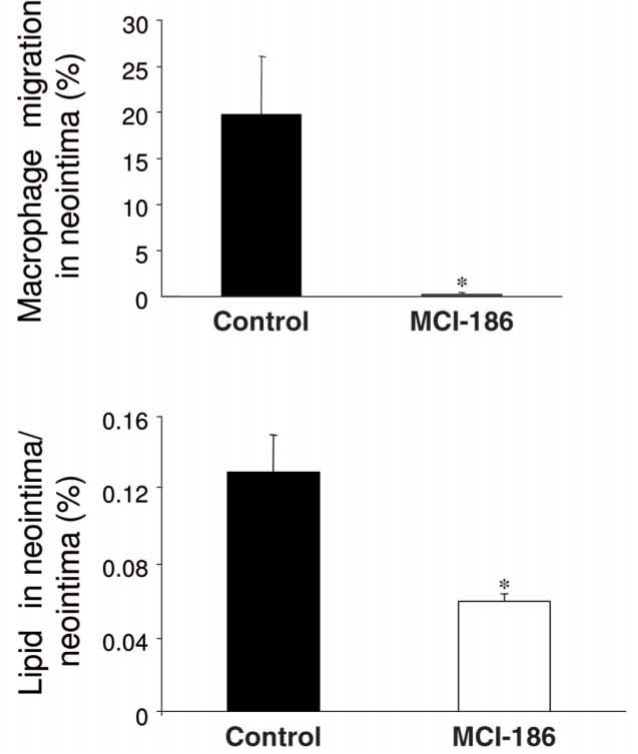

Fig 3. Anti-inflammatory action of MCI-186 is shown. (A) MCI-186 significantly reduced the expression of superoxide production in balloon-injured arteries. (B) MCI-186 inhibited migration of macrophages into the arterial wall. In the control group, macrophage migration was seen in the arterial wall, especially in the medial layer, whereas macrophage migration was inhibited in the MCI-186-treated group. The migration ratio, represented as macrophage migration/neointimal space, was $19.9 \pm 6.3 \%$ in the control group and $0.26 \pm 0.14 \%$ in the experimental group ( $<<0.05$ vs control group). Arrows indicate areas of macrophage migration. (C) Lipid deposition in the neointimal area was inhibited by MCI-186. Lipid deposition was observed in the control group, whereas it was inhibited in the MCI-186 group. The inhibition rate is shown in the graphs $(\mathrm{p}<0.05$ vs control group).

were stimulated by $\mathrm{IL}-1 \beta(30 \mathrm{ng} / \mathrm{ml})$ either with or without pre-incubation of $6 \mu \mathrm{mol} / \mathrm{L}$ MCI-186. Nuclear and cytoplasmic proteins were obtained using the method described elsewhere.25 Cell pellets were suspended in $100 \mu 1$ buffer A ( $10 \mathrm{mmol} / \mathrm{L} \mathrm{HEPES,} 10 \mathrm{mmol} / \mathrm{L} \mathrm{KCl}, 0.1 \mathrm{mmol} / \mathrm{L}$ EDTA, $1 \mathrm{mmol} / \mathrm{L}$ dithiothreitol and $0.5 \mathrm{mmol} / \mathrm{L} \mathrm{PMSF}$ ) for $15 \mathrm{~min}$. Cells were then lysed by adding $10 \%$ Nonidet P-40 (25 $\mu 1)$ and vigorously vortexed for $10 \mathrm{~s}$. Cytoplasmic protein was collected by centrifugation at $14,000 \mathrm{rpm}$ for $2 \mathrm{~min}$ and stored at $-80^{\circ} \mathrm{C}$. Nuclear pellets were resuspended in $50 \mu \mathrm{l}$ of buffer B (20 mmol/L HEPES, $0.4 \mathrm{~mol} / \mathrm{L} \mathrm{NaCl}, 1 \mathrm{mmol} / \mathrm{L}$ EDTA, $1 \mathrm{mmol} / \mathrm{L}$ dithiothreitol and $0.5 \mathrm{mmol} / \mathrm{L} \mathrm{PMSF}$ ) for $20 \mathrm{~min}$. Nuclear protein was collected by centrifugation at $14,500 \mathrm{rpm}$ for $5 \mathrm{~min}$ and stored at $-80^{\circ} \mathrm{C}$. Protein concentrations were determined by Bradford assay (Bio-Rad Laboratories, Hercules, CA, USA). Samples (20 $\mathrm{g}$ ) were fractionated by SDS-PAGE for NFK B, and Phospho k Ba, and then transferred to PVDF membranes (Millipore Co, Bedford, MA, USA). The membranes were incubated with NFK B p65 rabbit polyclonal Ab (1:4,000), and phosphok Ba (Ser32/36) mouse monoclonal Ab (1:2,000; Cell Signaling Technology, Inc, Danwers, MA, USA), followed by anti-rabbit IgG $\mathrm{Ab}$ and anti-mouse $\operatorname{IgG} \mathrm{Ab}$ conjugated with horseradish peroxidase (SantaCruz Biotechnology). We detected protein bands using chemiluminescence reagent Amersham ECL plus (GE Healthcare, Buckinghamshire, $\mathrm{UK})$.

\section{Quantitative Histopathology}

Neointimal thickness, neointimal lipid deposition and macrophage migration were determined using NIH image software. Neointimal thickness was calculated from the ratio of neointima/media and neointima/lumen. Lipid deposition and macrophage migration was calculated as the ratio of positively stained areas compared to the respective neointimal space. Three cross-sections were made for each RCCA specimen and examined. The average ratio \pm SEM is presented.

\section{Statistical Analysis}

All results are expressed as the mean \pm SEM. Group differences for continuous variables were determined by analysis using Student's t-test. P-values of $<0.05$ were considered statistically significant. 
A

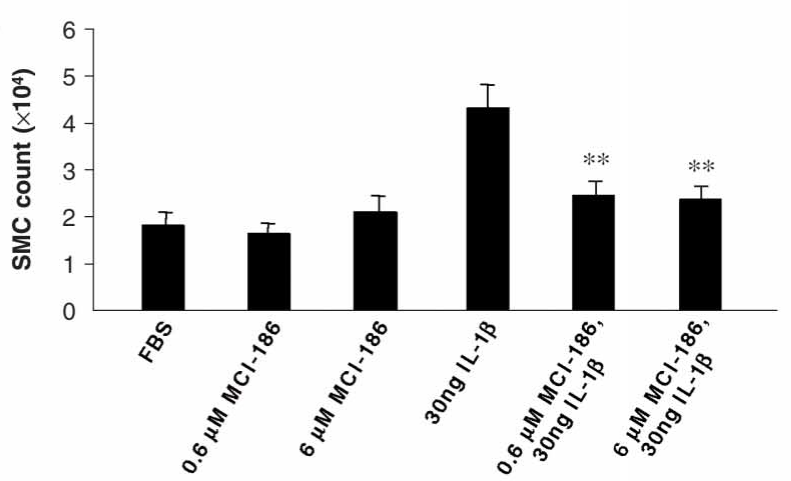

B
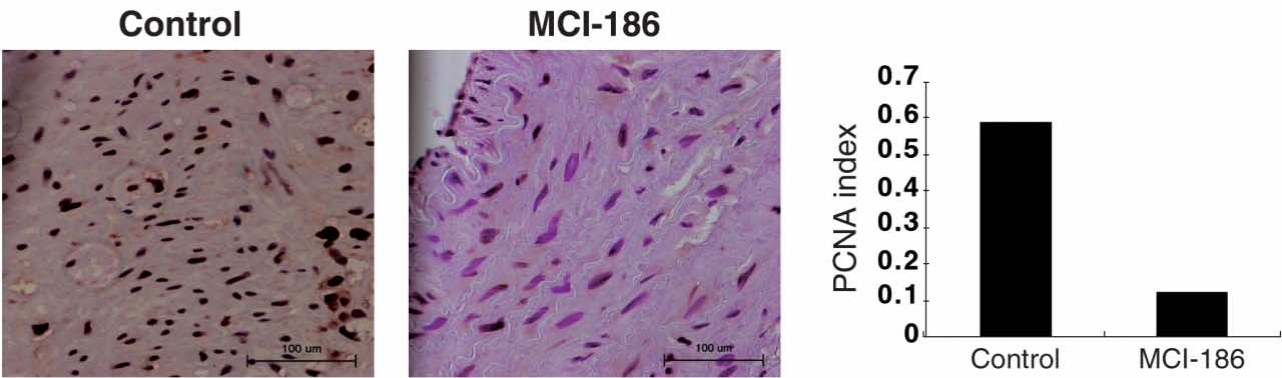

Fig 4. Attenuation of cell proliferation by MCI-186. (A) MCI-186 inhibited IL-1B-induced proliferation of smooth muscle cells from rabbit aorta (RASMC). The graph shows the effect of MCI-186 on RASMC proliferation when stimulated by IL-13. Lane 1, cells with FBS only; Lanes 2 and 3, cells with MCI-186; Lane 4, cells with IL-13 only; Lanes 5 and 6 , cells with MCI-186 and IL- $\mathbb{\beta}$. MCI-186 significantly attenuated IL- $1 \beta$-induced RASMC proliferation. (B) Cell proliferation in a balloon-injured artery was examined by immunostaining with anti-proliferating cell nuclear antigen (PCNA) antibody. The number of PCNA-positive cells decreased in the experimental group compared with the control group. The PCNA index was calculated from 5 different locations in each section for each group. SMC, smooth muscle cells; FBS, fetal bovine serum.

\section{Results}

MCI-186 Prevented the Progression of Atherosclerosis In Vivo in the Rabbit Balloon Injury Model

As shown in Figs 1A,B,E,F, neointimal thickness was detected in the RCCA of the control group, with the major constituent found to be SMC, which was determined by the presence of a-SMC actin-positive cells (Figs 1E,F). In the control group, the ratio of neointimal thickness/medial thickness was $0.468 \pm 0.08$ and MCI-186 treatment decreased the ratio to $0.187 \pm 0.01$ in the experimental group ( $<<0.02$ vs control group; Fig 1C). Furthermore, the ratio of neointimal thickness/vascular lumen was $0.698 \pm 0.09$ in the control group and $0.25 \pm 0.01$ in the experimental group ( $<<0.01$ vs control group; Fig 1D), and the lipid deposition ratio in the control group was $0.13 \pm 0.02$ and decreased to $0.06 \pm 0.003$ in the experimental group ( $<<0.05$ vs control group; Fig 3C). The value of PCNA in areas with neointimal formation was directly proportional to cell growth, as demonstrated by the decreased cell growth after the addition of MCI-186 (Fig 4B).

\section{MCI-186 Treatment Inhibited the Inflammatory Response to Balloon Injury}

MCI-186 also reduced the production of superoxide anion in balloon-injured arteries, whereas SMC of the control arteries stained positive for the superoxide anion, as confirmed by DHE staining (Fig 3A). Since neointimal thickness was inhibited by MCI-186, we examined its possible role in the inhibition of macrophage migration. As shown in Fig 3B, in the control group, macrophage migration into the neointimal areas was detected $(19.9 \pm 6.3 \%)$, whereas in the MCI-186-treated experimental group, the migration of macrophages was inhibited $(0.26 \pm 0.14 \%)$ ( $\mathrm{p}<0.05$ vs control group). MCI-186 significantly attenuated the expression of E-selectin in injured arteries, as confirmed by immunofluorescent staining (Fig 2).

\section{Serum Cholesterol Level Unchanged by MCI-186}

Although MCI-186 inhibited the development of neointimal thickness, lipid deposition and macrophage migration, total cholesterol levels were not reduced. After 4 weeks, the total cholesterol level increased from $24.57 \pm 4.32 \mathrm{mg} / \mathrm{dl}$ to $1,205.8 \pm 153.5 \mathrm{mg} / \mathrm{dl}$ in the control group and from $28.67 \pm 7.1 \mathrm{mg} / \mathrm{dl}$ to $1,185.8 \pm 199 \mathrm{mg} / \mathrm{dl}$ in the experimental group. The differences between the 2 groups at the starting $(\mathrm{p}=0.29$ vs control) and endpoint ( $\mathrm{p}=0.47$ vs control) were not significantly different. Lipid peroxidation levels remained unchanged in both groups (data not shown).

MCI-186 Inhibited IL- $\beta$-Induced RASMC Growth In Vitro

IL- $\beta$ induced dose-dependent growth of RASMC, in concentrations ranging from $3 \mathrm{ng} / \mathrm{ml}(\mathrm{p}<0.05$ vs $10 \%$ FBS) to $30 \mathrm{ng} / \mathrm{ml}(\mathrm{p}<0.01$ vs $10 \% \mathrm{FBS})$, and yet cell viability remained unchanged (data not shown). In 10\% FBS-supplemented medium without IL-1 $\beta$, the number of cells increased $1.3 \pm 0.03$ times compared with the starting point, whereas the addition of IL- $\mathbb{\beta}$ increased RASMC growth by $2.6 \pm 0.29$-fold. Without IL- $\mathbb{\beta}$ stimulation, MCI-186 did affect cell growth, whereas with IL-1 $\beta$, MCI-186 inhibited growth increase to only $1.39 \pm 0.16$-fold with $0.6 \mu \mathrm{mol} / \mathrm{L}$ $(\mathrm{p}<0.01$ vs IL- $\mathbb{\beta}$ alone) and $1.35 \pm 0.15$-fold with $6 \mu \mathrm{mol} / \mathrm{L}$ of MCI-186 ( $\mathrm{p}<0.01$ vs IL- $\mathbb{\beta}$ alone) (Fig 4A). As the differ- 
A
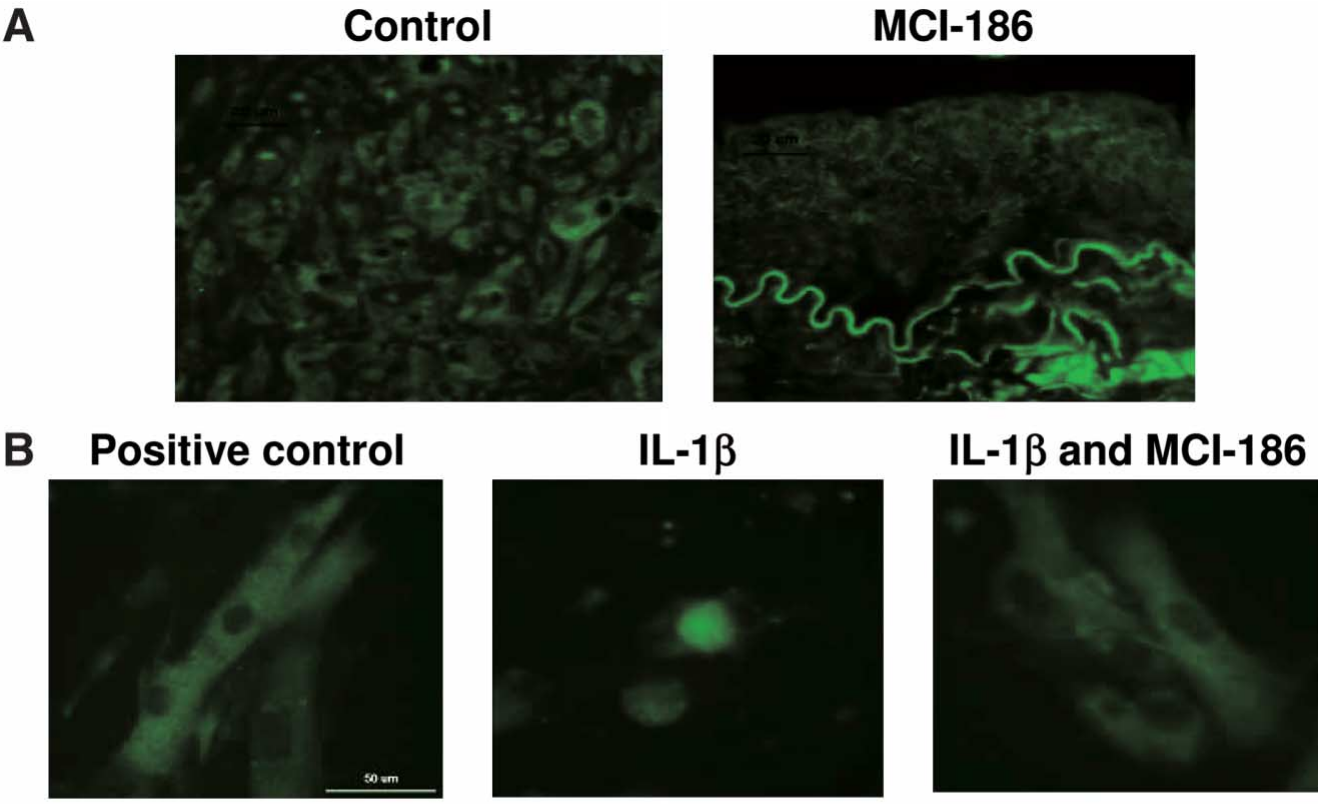

C

Nuclear NFKB
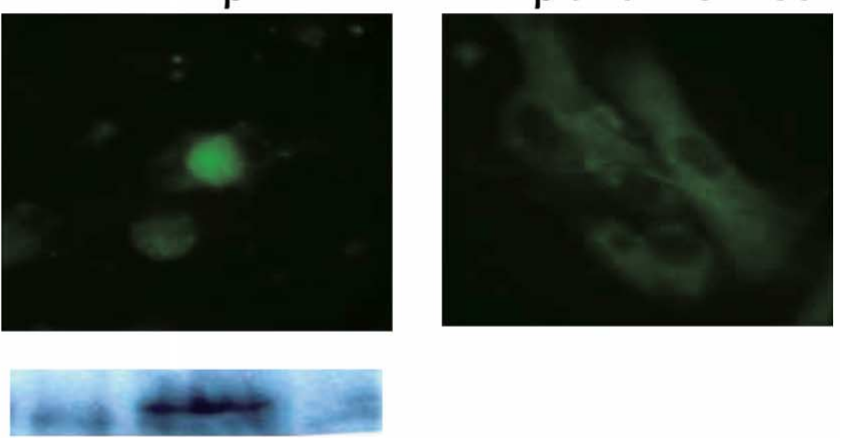

\section{Cytoplasmic NFKB}

\section{Phospho IkB $\alpha$}

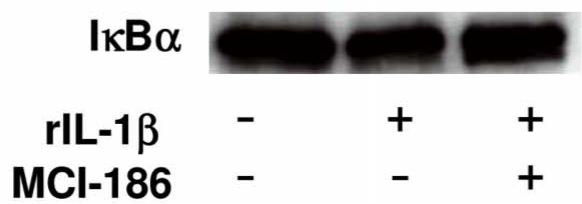

Fig 5. MCI-186 inhibited the activation of nuclear factork B (NFK B). (A) In the control group, nuclear translocation of p65 NFk B was detectable, whereas it was not seen in the experimental group B. (B) Representative immunocytochemical analysis revealed localization of p65 in the nucleus when stimulated by IL- $\mathbb{\beta}$, whereas MCI-186 prevented nuclear translocation. (C) Human umbilical vein endothelial cells were treated with $100 \mathrm{IU}$ of IL-1B alone or in combination with $6 \mu \mathrm{mol} / \mathrm{L}$ of MCI-186. NFK B and phosphorylated $\mathrm{k}$ Ba protein levels were measured after $1 \mathrm{~h}$ by western blot analysis. $\mathrm{K}$ Ba kinase was used as an internal control. MCI-186 inhibited the nuclear translocation of p65 NFK B under IL- 13 stimulation by inhibiting the phosphorylation of $\mathrm{k} \mathrm{Ba}$.

ence in inhibition between the 2 doses was not statistically significant, $6 \mu \mathrm{mol} / \mathrm{L}$ was used as the dose for MCI-186 in the experiments that followed, as it corresponds to the dosage used clinically in acute cerebral ischemia.

\section{MCI-186 Inhibited the Activation of NF $\mathrm{K} B$}

We attempted to determine whether MCI-186 has any effect on NFK B activation in vivo as well. In the control rabbits, we detected nuclear translocation of p65 NFK B in the neointimal areas (Fig 5A), whereas it was not observed in the experimental group (Fig 5A). We examined whether RASMC proliferation was inhibited through an IL- $1 \beta$ induced NFK B activation pathway (Fig 5B). Without IL- $\beta$, the rate of nuclear translocation of p65 NFK B was $2 \pm 1.22 \%$, which increased to $19.82 \pm 3.75 \%$ with $30 \mathrm{ng} / \mathrm{ml}$ of IL- $1 \beta$. The addition of MCI-186 treatment reduced the IL- $\mathbb{\beta}$-induced nuclear translocation rate to $4.13 \pm 1.08 \%$ ( $p<0.01$ vs IL- $\mathbb{\beta}$ alone). This result was further confirmed by western blotting using HUVEC stimulated by IL- $\beta$ in the presence or absence of MCI-186 (Fig 5C). Furthermore, MCI-186 blocks
NFK B activation in the phosphorylation stage of $\mathbf{k} \mathrm{Ba}$, thereby preventing the nuclear translocation of NFK B. These results showed that MCI-186 inhibits the nuclear translocation of p65 NFK B in vivo, as well as in vitro.

\section{Discussion}

The major findings of the present study revealed that MCI-186 treatment reduces the inflammatory response and progression of neointimal hyperplasia in balloon-injured rabbits fed a $1 \%$ high cholesterol diet for 1 month. In vivo experiments revealed a reduction in neointimal thickness, migration of macrophages and E-selectin expression, and attenuated superoxide production and lipid deposition in MCI-186-treated groups. In vitro experiments revealed reduced proliferation of SMC and the inhibition of NFK B activation in the MCI-186 treated groups.

$\mathrm{NFK} \mathrm{B}$ is involved in the regulation of genes responsible for SMC proliferation, migration of SMC into the injured site, expression of EC adhesion molecules and, thereby, 
transformation of monocytes into macrophages ${ }^{11}$ In the present study, we measured the effect of MCI-186 on NFK B activation. Both our in vitro and in vivo data showed that MCI-186 inhibited NFk B nuclear translocation. Free radicals and inflammatory cytokines are the causative agents of NFK B activation. MCI-186 is a known antioxidant that scavenges for free radicals and, thereby, the nuclear translocation ofk $B$ is inhibited.

Extensive proliferation of vascular SMC is considered to be the hallmark of atherosclerosis.,2 The genes that lead to the expression of factors that is responsible for cell proliferation is regulated by NFK B. In the present study, MCI-186 prevented the activation of NFK B and, moreover, resulted in decreased neointimal thickness in balloon-injured arteries and decreased proliferation in SMC stimulated by IL- $1 \beta$.

Expression of adhesion molecules is an important step in the chemotaxis of monocytes into the arterial intima 26 In the present study, we measured the expression of E-selectin in injured arteries. E-selectin expression was not observed in the MCI-186-treated RCCA of balloon-injured rabbits. Double immunofluorescence showed that E-selectin expression coincided with CD-31, a marker for ECs in balloon-injured arteries, whereas the upregulation of E-selectin molecules was not observed in the MCI-186-treated rabbits. Being an inhibitor of NFK B, MCI-186 could have attenuated E-selectin expression.

As a radical scavenger, MCI-186 absorbs free radicals, reduces superoxide production in balloon-injured arteries, reduces chronic stimulation of ECs and causes the downregulation of expression of adhesion molecules, leading to decreased monocyte migration. Hence, the differentiation of monocytes into macrophages is inhibited. This might have resulted in reduced neointimal thickness with decreased SMC proliferation and migration.

Although statins and anti-hypertensive drugs are effective in preventing atherosclerosis, secondary measures, such as anti-inflammatory agents and antioxidants, also have proved beneficial27-29 In this aspect, MCI-186 will be a useful drug in preventing early, as well as late, stages of atherosclerosis by attenuating the expression of adhesion molecules and SMC proliferation. Restenosis is the end result of the reactive proliferation of cells of the vessel wall after angioplasty 30 Thus, it is clear that an agent that suppresses cell proliferation may suppress restenosis. Since MCI-186 significantly prevents neointimal proliferation, it could be a prospective agent for preventing re-occlusion after percutaneous coronary intervention (PCI). MCI-186 can be used in adjunction with anti-thrombotic drugs, such as aspirin and ticlopidine, after PCI $3{ }^{1}$ In conclusion, MCI186, as well as its antioxidative action, possesses antiinflammatory properties, such as inhibiting the NFK B molecule. To our knowledge, this is the first study that demonstrates the mechanism of inhibition of neoinitmal hyperplasia in balloon-injured rabbits by the radical scavenger MCI-186.

\section{References}

1. Ross R. The pathogenesis of atherosclerosis: A perspective for the 1990s. Nature 1993; 362: 801-809.

2. Ross R. Cell biology of atherosclerosis. Annu Rev Physiol 1995; 57: 791-804.

3. Ross R. Atherosclerosis-an inflammatory disease. $N$ Engl J Med 1999; 340: $115-126$.

4. Lusis A. Atherosclerosis. Nature 2000; 407: 233-241.

5. Schwartz S. The Iitima: A new soil. Circ Res 1999; 85: 877-879.
6. Osterud B, Bjorklid E. Role of monocytes in atherogenesis. Physiol Rev 2003; 83: 1069-1112.

7. Linton M, Fazio S. Macrophages, inflammation, and atherosclerosis. Int J Obes Relat Metab Disord 2003; 27(Suppl 3): S35-S40.

8. Schwartz S. Smooth muscle migration in atherosclerosis and restenosis. J Clin Invest 1997; 99: 2814-2816.

9. Madamanchi N, Vendrov A, Runge M. Oxidative stress and vascular disease. Atheroscler Thromb Vasc Biol 2005; 25: 29-38.

10. Sasu S, Beasley D. Essential roles of K B kinasesa and $\beta$ in serumand IL-1-induced human VSMC proliferation. Am J Physiol Heart Circ Physiol 2000; 278: H1823-H1831.

11. DeWinther M, Kanters E, Kraal G, Hofker M. Nuclear factor $\mathrm{K} B$ signaling in atherogenesis. Atheroscler Thromb Vasc Biol 2005; 25: 904-914.

12. May MJ, Ghosh S. Rel/NFk B and k B proteins: An overview. Cancer Biol 1997; 8: 63-73.

13. Monaco C, Paleolog E. Nuclear factor K B: A potential therapeutic target in atherosclerosis and thrombosis. Cardiovasc Res 2004; 61: $671-682$.

14. Jawien J, Gajda M, Mateuszuk L, Olszanecki R, Jakubowski A, Szlachcic A, et al. Inhibition of Nuclear factork B attenuates atherosclerosis in apoE/LDLR-Double knockout mice. J Physiol Pharmacol 2005; 56: 483-489.

15. Hayashi $\mathrm{K}$, Takahata $\mathrm{H}$, Kitagawa N, Kitange G, Kamingo M, Shibata S. N-acetyl cysteine inhibited nuclear factor-kappa B expression and the intimal hyperplasia in rat carotid arterial injury. Neurol Res 2001; 23: 731-738.

16. Yamamoto Y, Kuwahara T, Watanabe K. Antioxidant activity of 3methyl-1-phenyl-2-pyrazolin-5-one. Redox Rep 1996; 2: 333-338.

17. Higashi Y, Jitsuiki D, Chayama K, Yoshizumi M. Edaravone (3methyl-1-phenyl-2-pyrazolin-5-one), a novel free radical scavenger, for treatment of cardiovascular diseases. Recent Patents Cardiovasc Drug Discov 2006; 1: 85-93.

18. Suzuki R, Katare Gopalrao R, Maeda H, Rao P, Yamamoto M, Xing Y, et al. MCI-186 inhibits tumour growth through suppression of EGFR phosphorylation and cell cycle arrest. Anticancer Res 2005; 25: $1131-1138$.

19. Watanabe T, Morita I, Nishi H, Murota S. Preventive effect of MCI186 on 15-HPETE induced vascular endothelial cell injury in vitro. Prostaglandins Leukot Essent Fatty Acids 1988; 33: 81 -87.

20. Okabe T, Kishimoto C, Shimada K, Murayama T, Yokode M, Kita T. Effects of MCI-186 (edaravone), a novel free radical scavenger, upon experimental atherosclerosis in apolipoprotein E-deficient mice. Circ J 2006; 70: 1216-1219.

21. Xu Q. Mouse model of arterioslerosis: From arterial injuries to vascular grafts. Am J Pathol 2004; 165: 1-10.

22. Massaeli H, Austria A, Pierce G. Chronic exposure of smooth muscle cells to minimally oxidized LDL results in depressed inositol 1,4,5-triphosphate receptor density and $\mathrm{Ca}^{2+}$ transients. Circ Res 1999; 85: 515-523.

23. Wada Y, Sugiyama A, Kohro T, Kobayashi M, Takeya M, Naito M, et al. In vitro model of atherosclerosis using coculture of arterial wall cells and macrophage. Yonsei Med J 2000; 41: 740-755.

24. Guzik TJ, West NE, Pillai R, Taggart DP, Channon KM. Nitric oxide modulates superoxide release and peroxynitrite formation in human blood vessels. Hypertension 2002; 39: 1088-1094.

25. Dignam JD, Lebovitz RM, Roeder RG. Accurate transcription initiation by RNA polymerase II in a soluble extract from isolated mammalian nuclei. Nucleic Acids Res 1983; 11: 1475-1488.

26. Dong Z, Chapman S, Brown A, Frenette P, Hynes R, Wagner D. The combined role of P- and E-selectins in atherosclerosis. J Clin Invest 1998; 102: $145-152$.

27. Grundy SM. Statin trials and goals of cholesterol-lowering therapy. Circulation 1998; 97: 1436-1439.

28. Maron DJ, Fazio S, Linton MF. Current perspectives on statins. Circulation 2000; 101: 207-213.

29. Violi F, Micheletta F, Luliano L. Antioxidants and atherosclerosis. Eur Hart J Suppl 2002; 4: B17-B21.

30. Shah PK. Inflammation, neointimal hyperplasia, and restenosis: As the leukocytes roll, the arteries thicken. Circulation 2003; 107: 2175-2177.

31. Popma JJ, Berger P, Ohman M, Harrington RA, Grines C, Weitz J. Antithrombotic therapy during percutaneous coronary intervention. Chest 2004; 126: 576S-599S.

32. Morita H, Saito Y, Ohashi N, Yoshikawa M, Katoh M, Ashida T, et al. Fluvastain ameliorates the hyperhomocysteinemia-induced endothelial dysfunction: The antioxidative properties of fluvastatin. Circ J 2005; 69: 475-480. 